\title{
Determination of notch factors for transverse non-load carrying stiffeners based on numerical analysis and metamodeling
}

\author{
Josef Neuhäusler $^{1}$ (D) Klemens Rother $^{1}$
}

Received: 3 August 2021 / Accepted: 16 December 2021 / Published online: 21 January 2022

(c) The Author(s) 2022

\begin{abstract}
Stress concentration factors (SCFs) at weld toes and weld roots as required for the effective notch stress concept (see $[1,2])$ are usually computed using finite element analysis (FEA) which requires a certain amount of effort for model generation, the solving process, and postprocessing. Regression functions of many FEAs within given parameter bounds provide the possibility of a fast prediction of SCFs. This paper provides new and accurate regression formulae for the estimation of notch stresses at idealized weld geometries on the basis of multiple linear-elastic FEAs for the transverse stiffener (non-load carrying T-joint) under tension and bending of the load carrying slab. Regression of sampled finite element results has been performed using (a) second-order polynomial regression with coupling terms (PRC) and (b) artificial neural networks (ANN). The presented formulae are compared with several existing estimations of stress concentration factors. The new methods appear to show a higher quality of prognosis as well as apply to significant larger ranges of the geometrical parameters of the weld joint. The formulae presented here for the transverse stiffener add another welded joint to a series of similar surrogate models presented from Munich University of Applied Sciences in earlier publications and made available for use by the web-based tool SCF-Predictor.
\end{abstract}

IIW-Thesaurus keywords Elastic analysis · Finite element analysis $\cdot$ Surrogate models $\cdot$ Sampling $\cdot$ Notches $\cdot$ Transverse stiffeners

\section{Nomenclature}

Symbols, abbreviations

ANN [-]

$\alpha\left[^{\circ}\right]$

$b_{i}[-]$

$c_{k}[-]$

$d[\mathrm{~mm}]$

$E[\mathrm{MPa}]$

$e r r_{\text {rel }}[\%]$

FEA [-]
$F[\mathrm{~N}]$

$f_{a}[-]$

Artificial neural network

Flank angle

Bias vectors for artificial neural networks

Scalar multiplication parameter for the PRC method

Total model depth

Modulus of elasticity

Relative error

Finite element analysis

$f_{k}[-]$

$\boldsymbol{g}[-]$

$K_{f}[-]$

$K_{t}[-]$

$\boldsymbol{k}_{t}[-]$
Recommended for publication by Commission XIII - Fatigue of Welded Components and Structures

Josef Neuhäusler

josef.neuhaeusler@hm.edu

1 Department Mechanical, Automotive and Aerospace Engineering, Institute for Material and Building Research, Munich University of Applied Sciences, Dachauerstr. 98b, 80335 Munich, Germany
$K_{t, E S T}[-]$

$K_{t, \text { FEM }}[-]$

$K_{t, A N N}[-]$

Force

Ratio of weld seam width to sheet thickness

Value of geometric multiplication parameter for the PRC method Input vector for the ANN method Fatigue notch factor

Stress concentration factor Stress concentration factor, estimated Stress concentration factor, calculated by FEM

Stress concentration output vector of the ANN method

Stress concentration factor of the ANN method

$K_{t, P R C}[-]$

$K_{t, T S U J}[-]$

Stress concentration factor of the PRC method

Stress concentration factor of Tsuji's method

$K_{t, M O N A / B R E N / H E L L}[-] \quad$ Stress concentration factor of Monahan's or Brennan's or Hellier's method 


$\begin{array}{ll}K_{w}[-] & \begin{array}{l}\text { Ratio of notch stress to structural } \\ \text { stress }\end{array} \\ K_{w, \text { min }}[-] & \begin{array}{l}\text { Minimum ratio of notch stress to } \\ \text { structural stress }\end{array} \\ L[\mathrm{~mm}] & \text { Length of sheet } \\ M[\mathrm{~N} / \mathrm{mm}] & \text { Moment } \\ \nu[-] & \text { Poisson ratio } \\ \boldsymbol{\Phi}_{i}[-] & \text { Artificial neural network layer } \\ & \text { potential } \\ \text { PRC [-] } & \text { Polynomial regression with cou- } \\ & \text { pling terms } \\ \rho^{[\mathrm{mm}]} & \text { Notch radius } \\ S_{b}[\mathrm{MPa}] & \text { Nominal bending stress } \\ S_{t}[\mathrm{MPa}] & \text { Nominal tension stress } \\ \sigma_{n}[\mathrm{MPa}] & \text { Notch stress } \\ \sigma_{s}[\mathrm{MPa}] & \text { Structural stress } \\ t_{1}, t_{2}[\mathrm{~mm}] & \text { Sheet thicknesses } \\ \boldsymbol{W}_{\boldsymbol{i}}[-] & \text { Weight matrices of artificial neural } \\ & \text { networks } \\ \boldsymbol{x}_{\boldsymbol{i}, \text { gain }}[-] & \text { Gain input vector for artificial neu- } \\ \boldsymbol{x}_{\boldsymbol{i}, \text { offset }}[-] & \text { ral networks } \\ \boldsymbol{y}_{\boldsymbol{o}, \text { gain }}[-] & \text { Offset input vector for artificial } \\ \boldsymbol{y}_{\boldsymbol{o}, \text { offset }}[-] & \text { neural networks } \\ & \text { Gain output vector of artificial } \\ & \text { neural networks } \\ & \text { Offset output vector of artificial } \\ & \text { neural networks }\end{array}$

Indices, superscripts

$b$, bend

Bending

Tension

Full penetration

PRC method index

toe

and sheet thickness based on accuracy and computational efficiency, as can be seen in [2]. Depending on the selected size of the radius and group of material, FAT classes have been derived by backward calculations from experimentally obtained life data using this concept conforming modeling rule for the fictitious radius $\rho$. This way, the theoretical notch factor $K_{t}$ represents already the fatigue notch factor $K_{f}$. The notch stress concept as described in $[1,2]$ has been originally proposed by Seeger et al. [7] which was motivated on early works of Radaj [8] and Neuber [9].

Renken et al. [10] recently have shown an application of the notch stress concept for the analysis of scanned weld topographies and distributions of local SCFs. There exist several other contributions where weld topographies have been scanned and analyzed numerically. Alam et al. [11] investigated eccentric fillet joints in such way, while Liinalampi et al. [12] analyzed laser-hybrid welds with thin plates in a similar fashion. Ottersböck et al. [13] characterized actual weld geometry and stress concentrations of butt welds and compared numerical results with approximation solutions.

The goal of this paper is to provide computational efficient estimations for SCFs of transverse non-load carrying stiffeners for three distinct weld toe radii $\rho=1 \mathrm{~mm}$, $\rho=0.3 \mathrm{~mm}$, and $\rho=0.05 \mathrm{~mm}$ for supporting fatigue evaluations according to $[2,3]$. Two new surrogate models based on a large amount of samples processed using FEA of transverse non-load carrying stiffeners with varying geometrical parameters of flank angle $\alpha$, reference radius $\rho$, sheet thicknesses $t_{1}, t_{2}$, and weld seam thickness $a$ are provided. The paper extends an already investigated and published collection of the joint types (a) cruciform joints [14], (b) butt joints [15], and (c) load carrying T-joints [16].

The proposed estimations are compared to existing equations by Tsuji [17], Monahan [18], Brennan et al. [19], and Hellier et al. [20]. Similar analyses using artificial neural networks for nonlinear regression demonstrating a very good quality of prognosis have been published by Dabiri et al. [21]. The latter solution was done using a smaller application range of the parameters and only for full penetration welds. Because the ANN of this group was not published, a direct comparison with the proposed methods in the present paper was not possible. Since the application of ANN and advanced PRC for SCF estimation is a relatively new approach, these methods were chosen for this investigation. The methods appear to significantly reduce scatter in predicting SCFs for large ranges of the parameters considered.

\section{Numerical simulation of welded T-joints}

The numerical models of the transverse non-load carrying stiffeners cover the geometrical parameters given in Table 1 and 2 with the respective ranges of variables for sampling. 
Table 1 Parameter ranges of numerical model

\begin{tabular}{lll}
\hline Parameter & & Range \\
\hline Flank angle $\left[^{\circ}\right]$ & $\alpha$ & {$[110 ; 160]$} \\
Reference radius $[\mathrm{mm}]$ & $\rho$ & See Table 2 \\
Sheet thickness $[\mathrm{mm}]$ & $t_{1}, t_{2}$ & See Table 2 \\
Weld seam thickness & $a=f_{a} t_{1}$ & {$\left[0.1 t_{1} ; 0.9 t_{1}\right]$} \\
Length of the base plate $[\mathrm{mm}]$ & $L_{1}$ & 150 \\
Length of the attachment $[\mathrm{mm}]$ & $L_{2}$ & 50 \\
\hline
\end{tabular}

Table 2 Parameter ranges for space filling Latin hypercube samplings

\begin{tabular}{llllll}
\hline Subsystem & $\rho[\mathrm{mm}]$ & $t_{1}, t_{2}[\mathrm{~mm}]$ & $\alpha\left[^{\circ}\right]$ & $a=f_{a} t_{1}[\mathrm{~mm}]$ & Samples \\
\hline 1 & 1.0 & {$[5 ; 50]$} & {$[110 ; 160]$} & {$\left[0.1 t_{1} ; 0.9 t_{1}\right]$} & 1599 \\
2 & 0.3 & {$[1.5 ; 20]$} & {$[110 ; 160]$} & {$\left[0.1 t_{1} ; 0.9 t_{1}\right]$} & 1519 \\
3 & 0.05 & {$[0.25 ; 5]$} & {$[110 ; 160]$} & {$\left[0.1 t_{1} ; 0.9 t_{1}\right]$} & 1461 \\
\hline
\end{tabular}

Axial or angular misalignment are not covered in the finite element models. In case misalignments are present, they have to be covered as secondary effects in the SCF $K_{t}$ as presented in [1] or by reducing the allowable stress.

\subsection{Parametrization}

The linear-elastic FEAs were performed in ANSYS Mechanical $^{\mathrm{TM}} 18.1^{1}$ according to Fig. 1 and Table 1 and 2 . The models are loaded by tension and bending (see Fig. 2). For each load case, full penetration welds have been considered.

The following assumptions apply to the finite element models:

- No axial or angular misalignment is covered.

- The weld seam flank is modeled by a straight line.

- Quadratic PLANE183 elements with plane strain condition.

- Constant parameters for linear elastic material:

- Modulus of elasticity $E=210 G P a$

- Poisson ratio $\nu=0.3$

- Uniform tension or bending nominal stress of $S_{t}=S_{b}=1 M P a$.

- Evaluation of maximum principal stress $\sigma_{1}$ at the weld toe.

- The SCF $K_{t}=\frac{\sigma_{1}}{S_{t / b}}$ is defined as the ratio of maximum principal stress $\sigma_{1}$ at the weld toe to uniform tension or bending nominal stress of $S_{t}=S_{b}=1 M P a$.

\footnotetext{
1 ANSYS Mechanical ${ }^{\mathrm{TM}}$ is a trademark of ANSYS, Inc., Canonsburg, PA, USA (see http://www.ansys.com).
}

DVS Merkblatt 0905 [2] addresses three different reference radii $\rho=1.0 \mathrm{~mm} / 0.3 \mathrm{~mm} / 0.05 \mathrm{~mm}$ depending on the sheet thickness. Hence, the design space is additionally separated into a subsystem for each reference radius (see Table 2). Note that the equations presented in this paper provide SCFs based on maximum principal stress. Similar formulas could be derived on the basis of $\mathrm{v}$. Mises equivalent stress in the notch radius. In that case, Sonsino [22] suggests different FAT values for fatigue evaluation based on v. Mises equivalent stress values.

\subsection{Finite element modeling and sampling}

The finite element models are meshed with PLANE183 elements of quadratic order and with plane strain condition. The areas around the weld toes are mapped meshed with quadrilateral elements with element lengths of $0.05 \cdot \rho$ in the notch up to a depth of $0.4 \cdot \rho$. An exemplary finite element mesh is shown in Fig. 3. More detailed information on numerical modeling can be found in [14].

For each subsystem in Table 2, a space filling Latin hypercube sampling was created with optiSLang® 7.2.0². In total, 4579 samples were successfully simulated.

Further information on sampling and modeling can be found in $[14,15]$.

The parameter ranges in Table 2 have been chosen. They cover all and beyond of the parameter ranges of the older equations from other authors as presented in Section 3. These parameters are typical for arc welded transverse nonload carrying stiffeners.

\section{Known methods of notch factor estimation of T-joints}

This section shows already published methods for the estimation of SCFs. Their predictive quality will be compared with the newly proposed methods using polynomial regression with coupling terms (PRC) and artificial neural networks (ANN). Most of the older equations presented in this section are of simpler form than the presented solutions using PRC and ANN. Because of the more complex form of the new approaches, the models PRC and ANN basically have a better adaptability to the finite element-based data points which leads to smaller errors in predicting SCFs of geometry combinations within the allowable parameter ranges.

\footnotetext{
${ }^{2}$ optiSLang® is a trademark of Dynardo GmbH, Weimar, Germany (an ANSYS, Inc. company) (see https://www.dynardo.de/software/ optislang.hmtl).
} 
Fig. 1 Parametrized geometry of the T-joint with full penetration

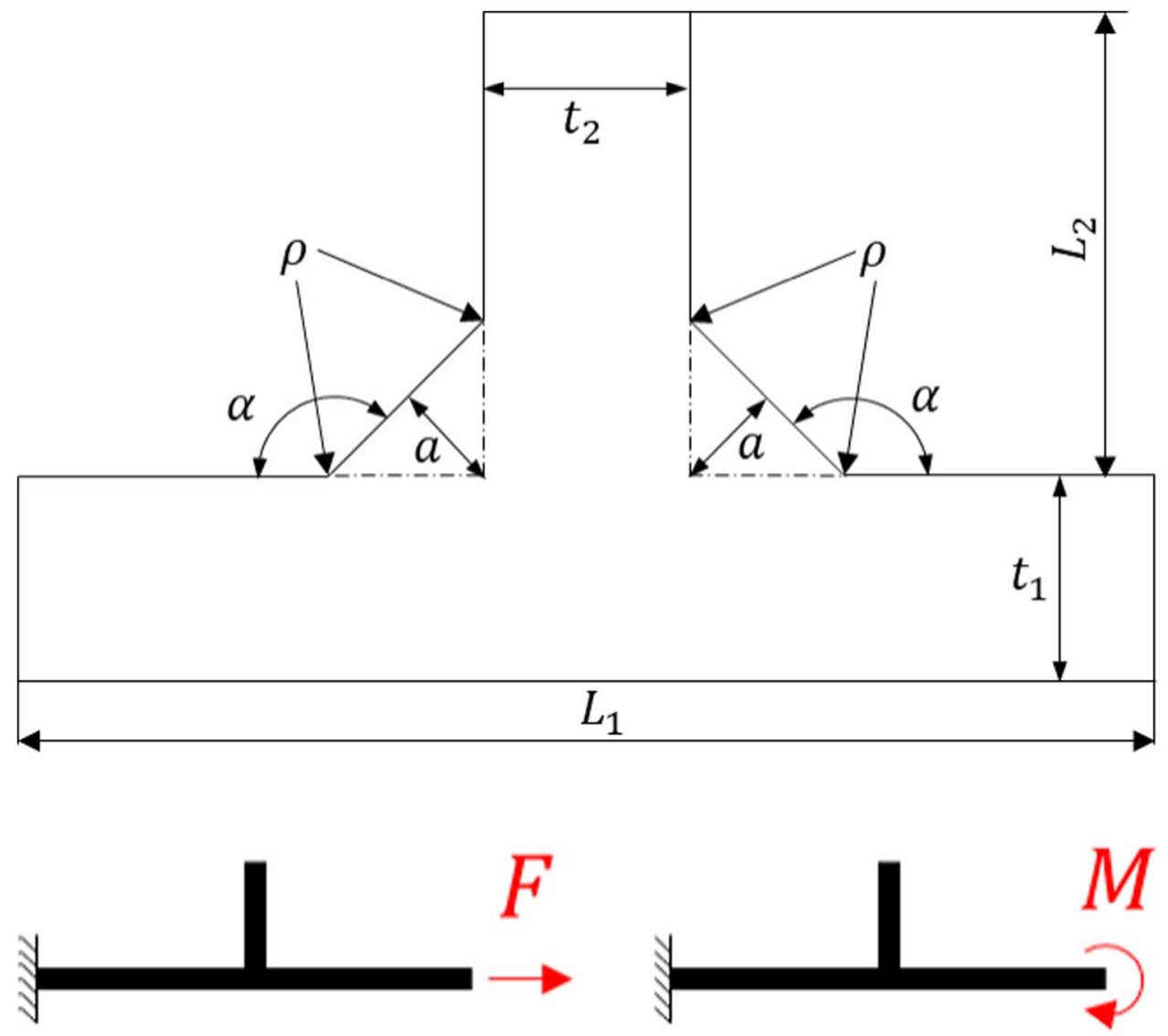

Fig. 2 Load cases 1 (tension) (left) and 2 (bending) (right)

\subsection{Method by Brennan}

Brennan et al. [19] derived regression equations for SCFs on the basis of 80 different weld toe T-butt geometries which are displayed in Table 5. The calculations were performed using linear elastic FEA and plane stress condition. The geometry validity limits are $120^{\circ}<\alpha<150^{\circ}$, $0.01<\rho / t_{1}<0.066$, and $0.3<L / t_{1}<4.0$ where $L$ is the attachment width.

\subsection{Method by Hellier}

Hellier et al. [20] published equations for SCFs of tension loaded T-joints which have a similar structure like the
Fig. 3 Complete finite element mesh (left) and mesh refinement in the notch at weld toes (right)

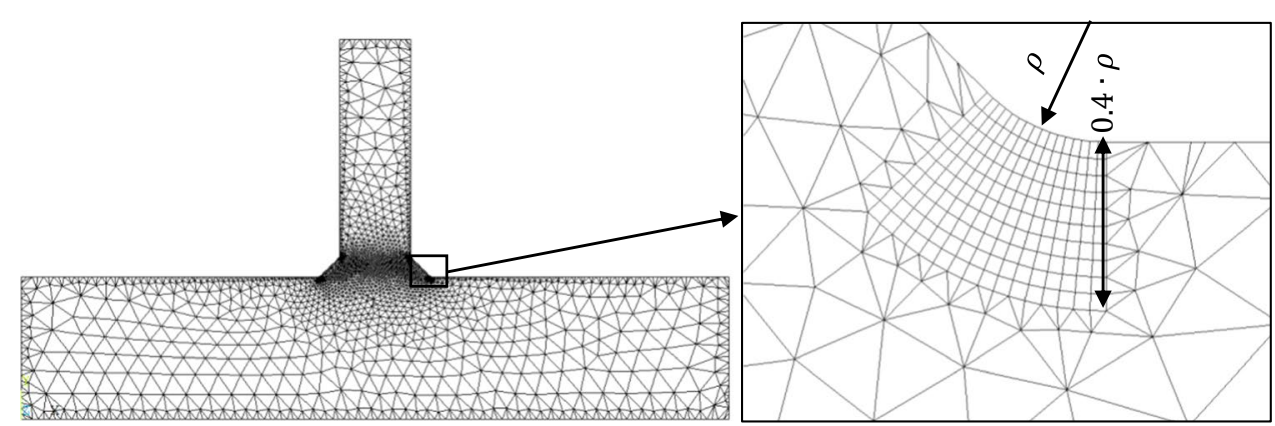


Table 3 Method by Tsuji

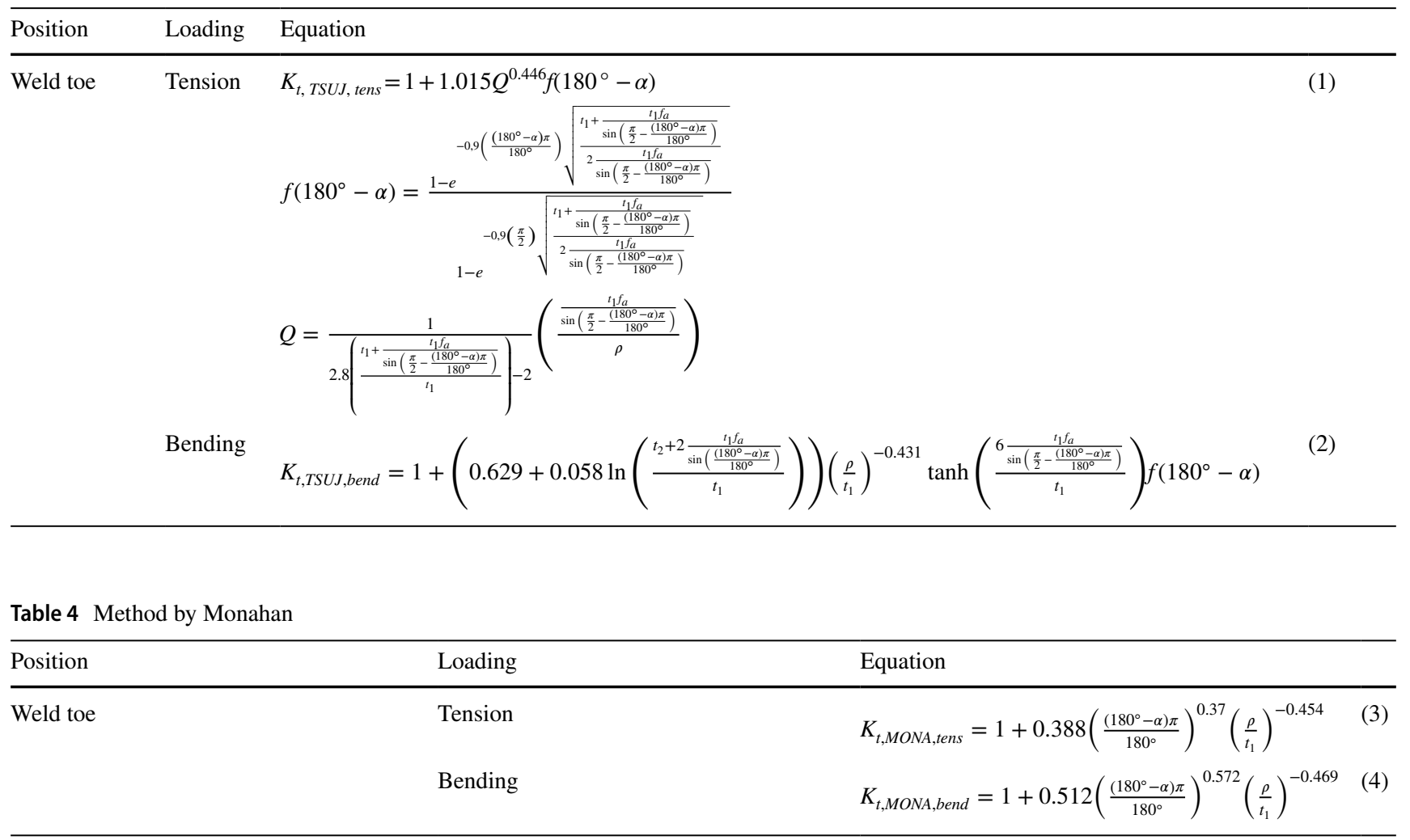

Table 5 Method by Brennan et al.

\begin{tabular}{|c|c|c|c|}
\hline Position & Loading & Equation & \\
\hline & & $L=t_{2}+2 \frac{t_{1} f_{a}}{\sin \left(\frac{\left(180^{\circ}-\alpha\right)}{180^{\circ}} \pi\right)} \gamma=\frac{\left(180^{\circ}-\alpha\right) \pi}{180^{\circ}}$ & \\
\hline \multirow[t]{2}{*}{ Weld toe (simplified) } & Tension & $K_{t, B R E N, \text { tens }}=1.027+0.271 \gamma^{0.261}\left(\frac{\rho}{t_{1}}\right)^{-0.47}\left(\frac{L}{t_{1}}\right)^{0.183}$ & (5) \\
\hline & Bending & $K_{t, B R E N, \text { bend }}=1.01+0.344 \gamma^{0.336}\left(\frac{\rho}{t_{1}}\right)^{-0.468}\left(\frac{L}{t_{1}}\right)^{0.233}$ & (6) \\
\hline \multirow[t]{2}{*}{ Weld toe (full) } & Tension & $\begin{array}{l}\quad K_{t, B R E N, \text { tens }}=1.1+0.067 \alpha-0.25\left(\frac{\rho}{t_{1}}\right)-0.04\left(\frac{L}{t_{1}}\right) \\
+0.003 \alpha^{2}-12\left(\frac{\rho}{t_{1}}\right)^{2}-0.014\left(\frac{L}{t_{1}}\right)^{2}+0.0164 \alpha^{3}-0.0005\left(\frac{L}{t_{1}}\right)^{3} \\
+0.00004\left(\frac{L}{t_{1}}\right)^{4}-0.3 \alpha\left(\frac{\rho}{t_{1}}\right)-0.023 \alpha\left(\frac{L}{t_{1}}\right)+0.91\left(\frac{\rho}{t_{1}}\right)\left(\frac{L}{t_{1}}\right)-8.3 \alpha^{2}\left(\frac{\rho}{t_{1}}\right) \\
+0.255 \alpha^{2}\left(\frac{L}{t_{1}}\right)+100.5 \alpha\left(\frac{\rho}{t_{1}}\right)^{2}-0.0792 \alpha\left(\frac{L}{t_{1}}\right)^{2} \\
-37.5\left(\frac{\rho}{t_{1}}\right)^{2}\left(\frac{L}{t_{1}}\right)+0.908\left(\frac{\rho}{t_{1}}\right)\left(\frac{L}{t_{1}}\right)^{2}+0.27 \alpha^{0.19}\left(\frac{\rho}{t_{1}}\right)^{-0.74}\left(\frac{L}{t_{1}}\right)^{0.25}\end{array}$ & (7) \\
\hline & Bending & $\begin{array}{l}K_{t, B R E N, \text { bend }}=1.14+0.13 \alpha-0.67\left(\frac{\rho}{t_{1}}\right)-0.083\left(\frac{L}{t_{1}}\right)+0.08 \alpha^{2}+28\left(\frac{\rho}{t_{1}}\right)^{2}-0.02\left(\frac{L}{t_{1}}\right)^{2} \\
+0.01 \alpha^{3}-0.0005\left(\frac{L}{t_{1}}\right)^{3}-0.00002\left(\frac{L}{t_{1}}\right)^{4}-4.3 \alpha\left(\frac{\rho}{t_{1}}\right)-0.09 \alpha\left(\frac{L}{t_{1}}\right)-1.03\left(\frac{\rho}{t_{1}}\right)\left(\frac{L}{t_{1}}\right)-13.7 \alpha^{2}\left(\frac{\rho}{t_{1}}\right) \\
+0.443 \alpha^{2}\left(\frac{L}{t_{1}}\right)+150 \alpha\left(\frac{\rho}{t_{1}}\right)^{2}-0.13 \alpha\left(\frac{L}{t_{1}}\right)^{2}-62\left(\frac{\rho}{t_{1}}\right)^{2}\left(\frac{L}{t_{1}}\right) \\
+1.53\left(\frac{\rho}{t_{1}}\right)\left(\frac{L}{t_{1}}\right)^{2}+0.005 \alpha^{3}\left(\frac{L}{t_{1}}\right)-30 \alpha\left(\frac{\rho}{t_{1}}\right)^{3}+3.57 \alpha\left(\frac{\rho}{t_{1}}\right)\left(\frac{L}{t_{1}}\right) \\
+5 \alpha\left(\frac{\rho}{t_{1}}\right)^{2}\left(\frac{L}{t_{1}}\right)+0.35 \alpha^{0.26}\left(\frac{\rho}{t_{1}}\right)^{-0.468}\left(\frac{L}{t_{1}}\right)^{0.3}\end{array}$ & (8) \\
\hline
\end{tabular}

equations by Brennan. In fact, the "simplified" version of the equation is exactly the same. Only the "full equation" differs from the one by Brennan, see Table 6 . The range of validity is also similar to the ones given by Brennan. 
Table 6 Method by Hellier

\begin{tabular}{lll}
\hline Position & Loading & Equation \\
\hline & & $L=t_{2}+2 \frac{t_{1} f_{a}}{\sin \left(\frac{\left(180^{\circ}-\alpha\right)}{180^{\circ}} \pi\right)} \gamma=\frac{\left(180^{\circ}-\alpha\right) \pi}{180^{\circ}}$ \\
Weld toe (simplified) & Tension & $K_{t, \text { HELL,tens }}=1.027+0.271 \gamma^{0.261}\left(\frac{\rho}{t_{1}}\right)^{-0.47}\left(\frac{L}{t_{1}}\right)^{0.183}$ \\
Weld toe (full) & Tension & $K_{t, \text { HELL,tens }}=0.889-0.302 \alpha+3.44\left(\frac{\rho}{t_{1}}\right)+0.529\left(\frac{L}{t_{1}}\right)+0.012 \alpha^{2}$ \\
& & $+104\left(\frac{\rho}{t_{1}}\right)^{2}-0.633\left(\frac{L}{t_{1}}\right)^{2}-0.614 \alpha^{3}+0.18\left(\frac{L}{t_{1}}\right)^{3}-0.018\left(\frac{L}{t_{1}}\right)^{4}-35.5 \alpha\left(\frac{\rho}{t_{1}}\right)-0.153 \alpha\left(\frac{L}{t_{1}}\right)$ \\
& $+4.38\left(\frac{\rho}{t_{1}}\right)\left(\frac{L}{t_{1}}\right)+30.6 \alpha^{2}\left(\frac{\rho}{t_{1}}\right)-0.219 \alpha^{2}\left(\frac{L}{t_{1}}\right)-64.3 \alpha\left(\frac{\rho}{t_{1}}\right)^{2}+0.041 \alpha\left(\frac{L}{t_{1}}\right)^{2}-54.5\left(\frac{\rho}{t_{1}}\right)^{2}\left(\frac{L}{t_{1}}\right)$ \\
& $+0.595\left(\frac{\rho}{t_{1}}\right)\left(\frac{L}{t_{1}}\right)^{2}+\alpha^{0.68}\left(\frac{\rho}{t_{1}}\right)^{-0.299}\left(\frac{L}{t_{1}}\right)^{0.263}$
\end{tabular}

\section{New methods of notch factor determination}

In this section, the two methods for the derivation of estimation formulae for SCFs are presented. The input values for the estimations shall be the geometrical parameters according to Table 1 and 2, whereas the output value is a single scalar value, the $\mathrm{SCF}$ based on the maximum principle stress $\sigma_{1}$.

\subsection{Polynomial regression with coupling terms (PRC method)}

The polynomial regression of quadratic order with coupling terms is carried out in optiSLang ${ }^{\circledR}$ 7.2.0. Equation (11) shows how the SCF is calculated with the respective factors $c_{k} \bullet f_{k}\left(t_{1}, \alpha, f_{a}\right)$ according to Table 12 . The restrictions for the equation can be found in Table 7 .

The nomenclature of the SCF for each reference radius and loading type is determined in Table 8 .

$K_{t, P R C}=\sum_{k=1}^{10} c_{k} \bullet f_{k}\left(t_{1}, \alpha, f_{a}\right)$

The three parameters $\left(t_{1}, \alpha, f_{a}\right)$ yield a maximum of 10 terms for the estimation of a SCF. The 10 terms result from the three parameters, their squares, each combination of two parameters, and one fixed term. In case one of these terms does not significantly affect the SCF, they are filtered out by optiSLang. The default filter settings have been used.

Table 7 Restrictions of the PRC method

\begin{tabular}{|c|c|c|c|}
\hline $\begin{array}{l}\text { Parameter combina- } \\
\text { tion }\end{array}$ & $t_{1}, t_{2}[\mathrm{~mm}]$ & $\frac{t_{1}}{t_{2}} \operatorname{or} \frac{t_{2}}{t_{1}}$ & $f_{a}$ \\
\hline \multirow[t]{3}{*}{ Restriction } & $5 \ldots . \ldots 0$ for $\rho=1.00 \mathrm{~mm}$ & $\frac{1}{3}<\frac{t_{1 / 2}}{t_{2 / 1}}<3$ & $0.1 \ldots 0.9$ \\
\hline & $\begin{array}{l}1.5 \ldots 20 \text { for } \\
\rho=0.30 \mathrm{~mm}\end{array}$ & & \\
\hline & $\begin{array}{l}0.25 \ldots .5 \text { for } \\
\rho=0.05 \mathrm{~mm}\end{array}$ & & \\
\hline
\end{tabular}

\subsection{Application of artificial neural networks (ANN method)}

With the help of Matlab's Neural Network Toolbox, an artificial neural network (ANN) was derived for each SCF. The data has been randomly divided into three subsets: $70 \%$ training data, $15 \%$ validation data, and $15 \%$ testing data. The ANN is fitted to the training data. During training the validation set is used to measure network generalization and to stop training when generalization stops improving. Testing data has no effect on training of the ANN and is only used as independent measure for the network performance and quality of prognosis. Levenberg-Marquardt was chosen as training algorithm. The ANN feed-forward neural network consists of three hidden layers, where each hidden layer consists of 4 neurons according to the 4 input parameters $\left(t_{1}, t_{2}, \alpha, f_{a}\right)$. The output layer yields the stress concentration factor as output value $\left(\mathbf{k}_{t}=\left(K_{t, A N N}\right)\right)$. A graphical representation of the ANN is displayed in Fig. 4.

Each layer consists of a weight matrix $\mathbf{W}_{i}$, a bias $\mathbf{b}_{i}$, and a layer potential $\boldsymbol{\phi}_{i}$ which is transferred to a hyperbolic tangent sigmoid transfer function.

The restrictions to this method are similar to the PRC method in Table 7. More information on neural networks can be found in Hagan et al. [23].

Table 8 Stress concentration factors for equations applying to maximum principal stress according to new method

\begin{tabular}{llll}
\hline Loading & $\begin{array}{l}\text { Sheet thickness } \\
t_{1}, t_{2}[\mathrm{~mm}]\end{array}$ & $\begin{array}{l}\text { Radius } \\
\rho[\mathrm{mm}]\end{array}$ & $\begin{array}{l}\text { Stress con- } \\
\text { centration } \\
\text { factor }\end{array}$ \\
\hline Tension & {$[0.25 ; 10]$} & 0.05 & $K_{t, P R C, t, 1}^{f . p .}$ \\
& {$[1.5 ; 20]$} & 0.3 & $K_{t, P R C, t, 2}^{f . p .}$ \\
& {$[5 ; 50]$} & 1 & $K_{t, P R C, t, 3}^{f . p .}$ \\
Bending & {$[0.25 ; 10]$} & 0.05 & $K_{t, P R C, b, 1}^{f . p .}$ \\
& {$[1.5 ; 20]$} & 0.3 & $K_{t, P R C, b, 2}^{f . p .}$ \\
& {$[5 ; 50]$} & 1 & $K_{t, P R C, b, 3}^{f . p .}$ \\
\hline
\end{tabular}




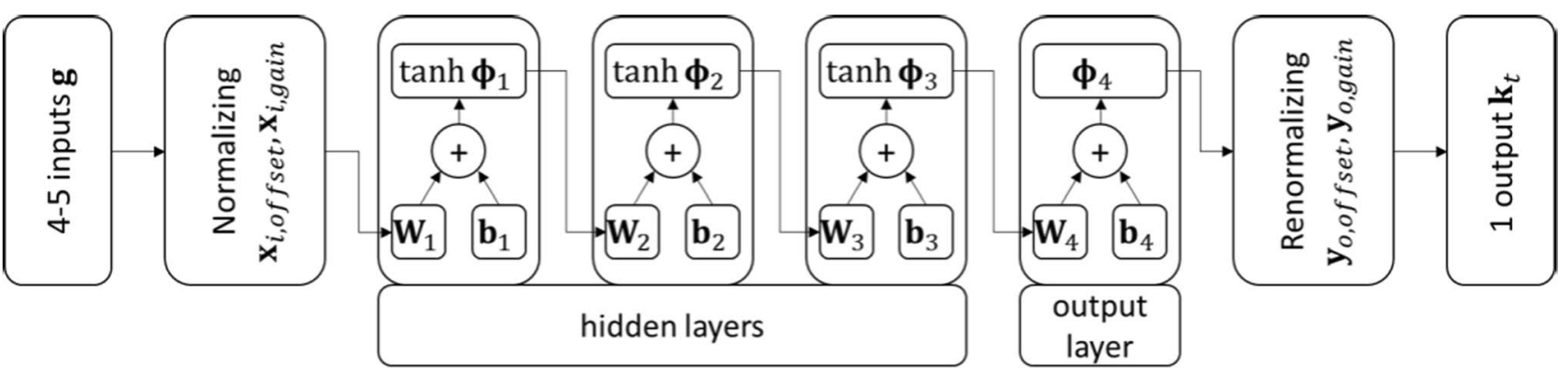

Fig. 4 Schematic structure of the artificial network

The multilayer approach with a low number of neurons in each hidden layer resulted in better estimation of stress concentration factors than a single-layer approach with a high number of neurons in the layer. Additionally, benefits in training and evaluation time could be accomplished.

The mathematical expressions for the used network can be found in Table $9^{3}$, and the corresponding normalization vectors, weighting matrices, and bias vectors can be found in Tables 13, 14, 15, 16, 17 and 18.

\section{Comparison of notch factor determination and quality}

In order to draw a comparison between the aforementioned existing methods and the newly proposed methods using PRC and ANN, the given restrictions have to be kept in mind. In the following figures, the evaluated finite element results have been selected according to these restrictions.

It should be noted that:

- Keep in mind that the ratio of notch stress to structural stress $K_{w}=\sigma_{n} / \sigma_{s}$ has to meet a lower limit $K_{w, \min }$; see Rother and Fricke [24]:

$$
K_{w, \min }=1.6 \text { for } \rho=1 \mathrm{~mm}
$$

$K_{w, \min }=2.13$ for $\rho=0.3 \mathrm{~mm}$

$K_{w, \min }=3.56$ for $\rho=0.05 \mathrm{~mm}$

\footnotetext{
3 . indicates the elementwise Hadamard product and $\oslash$ the elementwise Hadamard division.
}

In order to check $K_{w}$ against the minimum ratio $K_{w, \min }$, calculation of the structural stress is also required. This task has to be done by the user on top of the estimation of the SCF with the new equations.

\subsection{Comparison of methods for T-joints}

Figs. 5 and 6 show boxplots and probability plots for a normal distribution of the relative error which is calculated by:

$e r r_{r e l}=\frac{K_{t, E S T}-K_{t, F E M}}{K_{t, F E M}}[\%]$

Relative errors are calculated for all data points including training, validation, and testing data. The blue boxes in the boxplots show $50 \%$ of the data between the 25 and $75 \%$ quantiles. The distance between top and bottom of the blue box is the interquartile range. The red line is the median value. The black whiskers represent the last value within 1.5 times the interquartile range (the last value that is not an outlier) of the blue boxes.

Regarding the probability plots, the straight dashed lines represent a perfect normal distribution and are fitted to each data set.

Table 10 and 11 give additional statistical measures of the investigated data sets.

Table 9 Equations to be used for the ANN method

$\boldsymbol{\phi}_{1}=\mathbf{b}_{1}+\mathbf{W}_{1} \cdot\left(\left(\left(\mathbf{g}-\mathbf{x}_{i, \text { offset }}\right)^{\circ} \mathbf{x}_{i, \text { gain }}\right)-\mathbf{1}\right)$

$\boldsymbol{\phi}_{2}=\mathbf{b}_{2}+\mathbf{W}_{2} \cdot \tanh \left(\boldsymbol{\phi}_{1}\right)$

$\boldsymbol{\phi}_{3}=\mathbf{b}_{3}+\mathbf{W}_{3} \cdot \tanh \left(\phi_{2}\right)$

$\boldsymbol{\phi}_{4}=\mathbf{b}_{4}+\mathbf{W}_{4} \cdot \tanh \left(\phi_{3}\right)$

$\mathbf{k}_{t}=\left(\left(\boldsymbol{\phi}_{4}-\mathbf{y}_{o, \text { offset }}\right) \oslash \mathbf{y}_{o, \text { gain }}\right)-\mathbf{1}$ 
Fig. 5 Boxplot and probability plot of the relative errors for normal distribution-T-joint, load case 1 (tension)

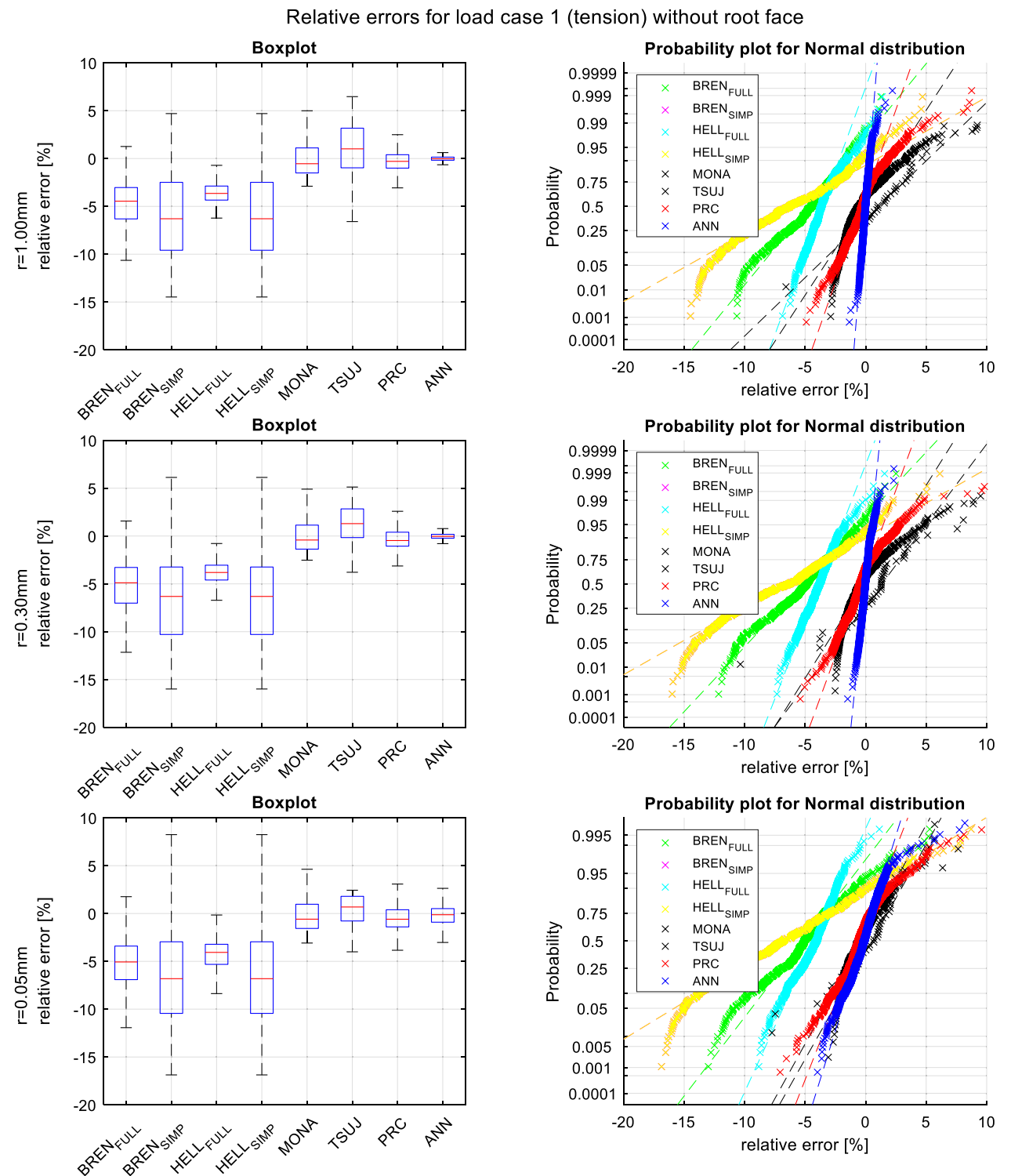

Figs. 5 and 6 show the comparison of relative errors of each method for transverse non-load carrying stiffeners with fully penetrated welds (without root face). It should be noted that the methods by Brennan et al. and Hellier et al. have been derived with the assumption of plane stress condition which leads to a slight systematical deviation compared to PRC and ANN. The methods by Monahan and Tsuji tend remarkably well towards a median of little error. However, all these methods undergo multiple tight restrictions for the design variables. In consequence they can only be applied in comparison with a smaller subset of finite element computations; see the total numbers of used samples in Table 10 and 11. The PRC and
ANN methods are capable of covering all evaluated finite element results and overall show improved performance in terms of significantly lower scattering around about zero or small relative error.

In terms of application of the newly introduced equations, the PRC method is slightly simpler to implement than the ANN method. The ANN will still yield more accurate predictions of SCFs. In order to reduce the computational effort for estimating SCFs for transverse non-load carrying stiffeners, the formulas for PRC and ANN will be provided via a programmed online solution which will be found in http://www.rother.userweb.mwn.de/scf-predi ctor.html [25]. 
Fig. 6 Boxplot and probability plot of the relative errors for normal distribution-T-joint, load case 2 (bending)
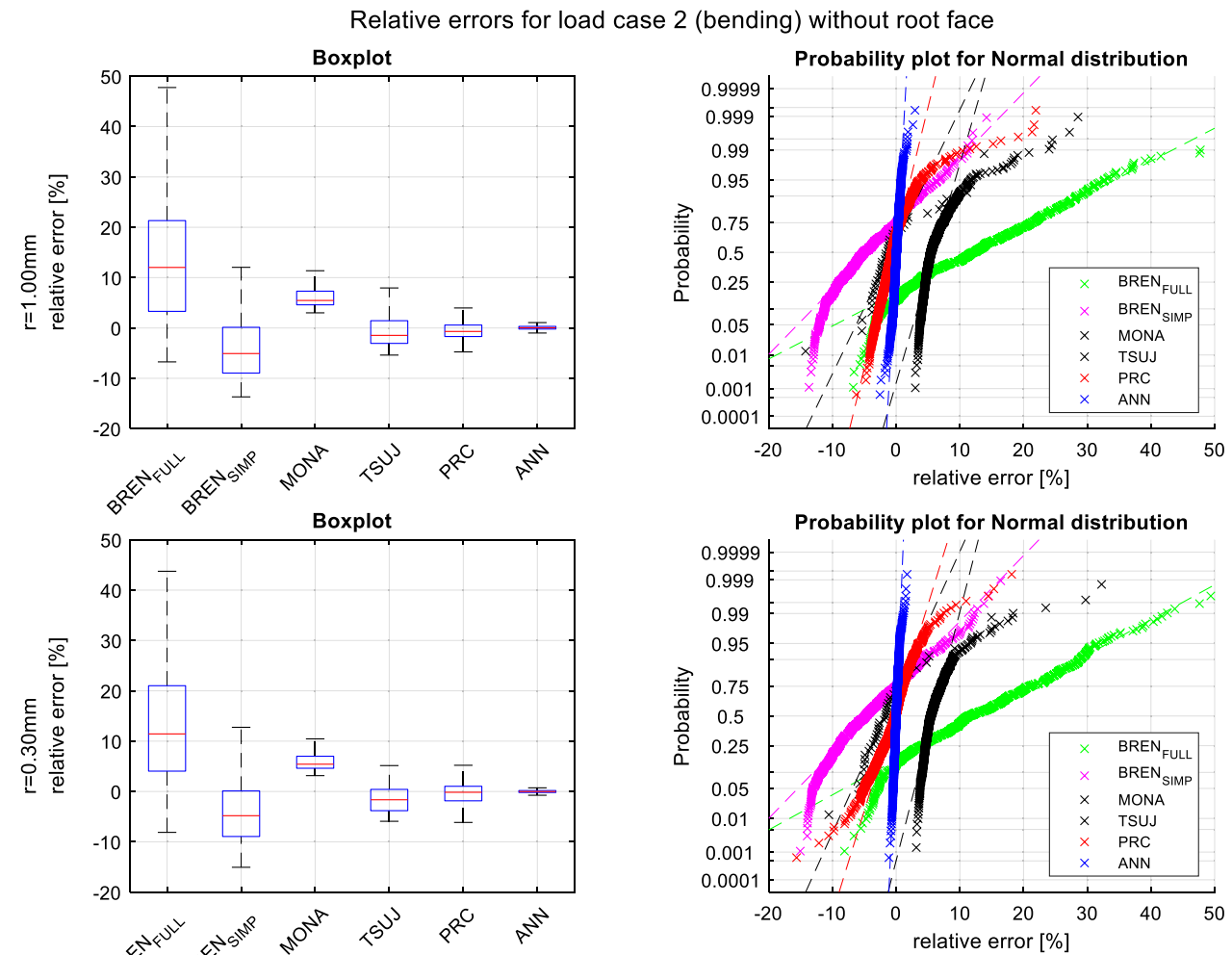

Probability plot for Normal distribution

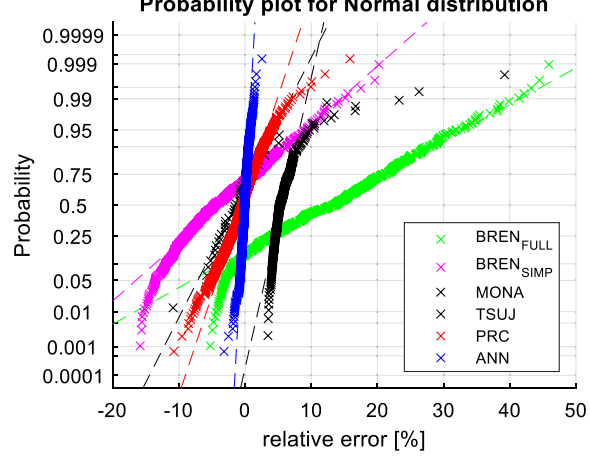

Table 10 Statistical data of all evaluated parameter combinations, load case 1 (tension)

\begin{tabular}{|c|c|c|c|c|c|c|c|c|}
\hline & \multicolumn{8}{|c|}{ Load case 1 (tension) without root face } \\
\hline & BREN $_{\mathrm{FULL}}$ & $\mathrm{BREN}_{\text {SIMP }}$ & HELL $_{\mathrm{FULL}}$ & HELL $_{\text {SIMP }}$ & MONA & TSUJ & $\mathrm{PRC}$ & ANN \\
\hline Neglected results & $39.62 \%$ & $39.62 \%$ & $39.62 \%$ & $39.62 \%$ & $54.53 \%$ & $94.75 \%$ & $3.6 \%$ & $0 \%$ \\
\hline Total number of used samples & 1381 & 1381 & 1381 & 1381 & 1040 & 120 & 2204 & 2287 \\
\hline Mean & $-4.98 \%$ & $-6.46 \%$ & $-3.88 \%$ & $-6.46 \%$ & $-0.04 \%$ & $0.90 \%$ & $-0.26 \%$ & $-0.06 \%$ \\
\hline Standard deviation & $2.90 \%$ & $4.72 \%$ & $1.48 \%$ & $4.72 \%$ & $1.91 \%$ & $2.79 \%$ & $1.79 \%$ & $0.80 \%$ \\
\hline $1 \%$ quantile & $-11.68 \%$ & $-15.79 \%$ & $-7.84 \%$ & $-15.79 \%$ & $-2.59 \%$ & $-8.53 \%$ & $-4.28 \%$ & $-2.62 \%$ \\
\hline $10 \%$ quantile & $-9.06 \%$ & $-12.78 \%$ & $-5.73 \%$ & $-12.78 \%$ & $-2.01 \%$ & $-2.49 \%$ & $-2.13 \%$ & $-0.76 \%$ \\
\hline Median & $-4.81 \%$ & $-6.46 \%$ & $-3.83 \%$ & $-6.46 \%$ & $-0.49 \%$ & $-1.02 \%$ & $-0.43 \%$ & $-0.04 \%$ \\
\hline $90 \%$ quantile & $-1.41 \%$ & $-0.35 \%$ & $-2.21 \%$ & $-0.35 \%$ & $3.02 \%$ & $3.80 \%$ & $1.84 \%$ & $0.59 \%$ \\
\hline $99 \%$ quantile & $1.75 \%$ & $4.54 \%$ & $0.07 \%$ & $4.54 \%$ & $9.10 \%$ & $8.09 \%$ & $5.18 \%$ & $2.29 \%$ \\
\hline
\end{tabular}


Table 11 Statistical data of all evaluated parameter combinations, load case 2 (bending)

\begin{tabular}{lllllll}
\hline & \multicolumn{2}{l}{ Load case 2 (bending) without root face } & & \\
\cline { 2 - 7 } & BREN $_{\text {FULL }}$ & BREN $_{\text {SIMP }}$ & MONA & TSUJ & PRC & ANN \\
\hline Neglected results & $39.31 \%$ & $39.31 \%$ & $53.88 \%$ & $94.76 \%$ & $4.1 \%$ & $0 \%$ \\
Total number of used samples & 1391 & 1391 & 1057 & 120 & 2198 & 2292 \\
Mean & $12.86 \%$ & $-4.02 \%$ & $5.98 \%$ & $-0.75 \%$ & $-0.47 \%$ & $0.004 \%$ \\
Standard deviation & $11.02 \%$ & $6.25 \%$ & $2.04 \%$ & $4.70 \%$ & $2.34 \%$ & $0.39 \%$ \\
$1 \%$ quantile & $-4.69 \%$ & $-14.31 \%$ & $3.45 \%$ & $-11.88 \%$ & $-7.16 \%$ & $-1.29 \%$ \\
$10 \%$ quantile & $-1.67 \%$ & $-11.53 \%$ & $4.09 \%$ & $-5.07 \%$ & $-3.33 \%$ & $-0.47 \%$ \\
Median & $12.32 \%$ & $-4.81 \%$ & $5.40 \%$ & $-1.58 \%$ & $-0.44 \%$ & $-0.01 \%$ \\
$90 \%$ quantile & $28.57 \%$ & $4.58 \%$ & $9.09 \%$ & $5.97 \%$ & $2.51 \%$ & $0.51 \%$ \\
$99 \%$ quantile & $42.40 \%$ & $12.23 \%$ & $23.12 \%$ & $14.16 \%$ & $8.45 \%$ & $1.30 \%$ \\
\hline
\end{tabular}

\section{Conclusion}

Existing estimations of SCFs at the weld toe of transverse non-load carrying stiffeners have been compared to two new estimations using PRC and ANN. The comparison has been drawn on the basis of FEAs with respect to the maximum principal stress in the weld toe assuming plane strain condition.
PRC and ANN not only increase the ranges of validity of existing SCF formulae but also show improved predictive quality which is shown by lower scattering of the relative errors.

The proposed methods may be incorporated into a programmed solution for the fast estimation of SCFs. The new methods will be programmed and made available for the community by http://rother.userweb.mwn.de/scf-predictor.html [25].

\section{Appendix}

Table 12 Regression formulae for PRC method for fully penetrated welds

\begin{tabular}{|c|c|c|c|c|c|c|c|}
\hline \multirow[t]{2}{*}{$k$} & \multirow[t]{2}{*}{$f_{k}$} & \multicolumn{6}{|l|}{$c_{k}$} \\
\hline & & $K_{t, P R C, t, 1}^{f . p .}$ & $K_{t, P R C, t, 2}^{f \cdot p .}$ & $K_{t, P R C, t, 3}^{f . p .}$ & $K_{t, P R C, b, 1}^{f . p .}$ & $K_{t, P R C, b, 2}^{f . p .}$ & $K_{t, P R C, b, 3}^{f \cdot p .}$ \\
\hline 1 & 1 & -8.60483 & -6.59428 & -5.72123 & -7.06393 & -6.56684 & -5.3789 \\
\hline 2 & $\alpha$ & 0.154805 & 0.122145 & 0.107518 & 0.13486 & 0.121658 & 0.107623 \\
\hline 3 & $t_{1}$ & 1.55803 & 0.301566 & 0.100052 & 2.05336 & 0.408816 & 0.14865 \\
\hline 4 & $f_{a}$ & & & & 2.19796 & 2.24764 & \\
\hline 5 & $\alpha^{2}$ & -0.000579344 & -0.000454423 & -0.000398838 & -0.000512678 & -0.000451622 & -0.000413855 \\
\hline 6 & $t_{1}^{2}$ & -0.060623 & -0.0028683 & -0.000386015 & -0.0824741 & -0.00425806 & -0.000529817 \\
\hline 7 & $f_{a}^{2}$ & & & & -0.579303 & -0.569353 & \\
\hline 8 & $\alpha t_{1}$ & -0.00624203 & -0.00116491 & -0.000368296 & -0.00910366 & -0.00174477 & -0.0006289 \\
\hline 9 & $\alpha f_{a}$ & & & & -0.0129674 & -0.0131744 & \\
\hline 10 & $t_{1} f_{a}$ & & & & 0.146999 & 0.0307963 & \\
\hline
\end{tabular}


Table 13 Neural network data for full penetration joints, tension loading, $\rho=1.00 \mathrm{~mm}$

Table 14 Neural network data for full penetration joints, tension loading, $\rho=0.30 \mathrm{~mm}$

\begin{tabular}{|c|c|c|c|c|c|c|c|}
\hline$x_{i, \text { offset }}=$ & $=\left[\begin{array}{r}110.0250 \\
5.20250 \\
5.51750 \\
0.10280\end{array}\right.$ & & $x_{i, \text { gain }}=$ & $=\left[\begin{array}{l}0.04004 \\
0.04467 \\
0.04498 \\
2.51256\end{array}\right.$ & & & \\
\hline \multicolumn{3}{|c|}{$y_{o, \text { offset }}=1.55949$} & \multicolumn{5}{|c|}{$y_{o, \text { gain }}=1.14896$} \\
\hline$b_{1}=$ & $\left.\begin{array}{l}-2.63750 \\
-1.52428 \\
-0.48874 \\
-0.30838 \\
-2.93238\end{array}\right]$ & & $b_{2}=\lfloor$ & $\begin{array}{c}1.78577 \\
-1.20924 \\
-0.32212 \\
-1.14307 \\
-2.16028\end{array}$ & $b_{3}=$ & {$\left[\begin{array}{c}1.96254 \\
-0.71252 \\
-0.13066 \\
-0.48033 \\
1.08610\end{array}\right]$} & $b_{4}=-0.11368$ \\
\hline$W_{1}=$ & $\begin{array}{c}0.12471 \\
1.22835 \\
-0.00449 \\
-0.03089 \\
0.09465\end{array}$ & $\begin{array}{c}-1.18246 \\
0.12309 \\
0.28566 \\
-0.22904 \\
-0.22888\end{array}$ & $\begin{array}{c}-0.04909 \\
0.00658 \\
-0.46518 \\
0.01333 \\
0.63831\end{array}$ & $\begin{array}{cc}9 & 0.03565 \\
& 0.01149 \\
8 & -0.77593 \\
0.00489 \\
0.21563\end{array}$ & & & \\
\hline$W_{2}=$ & $\begin{array}{c}-0.41445 \\
0.75332 \\
-1.16788 \\
-1.34748 \\
-0.49787\end{array}$ & $\begin{array}{c}1.17610 \\
0.43926 \\
1.40932 \\
-0.63935 \\
-0.94745\end{array}$ & $\begin{array}{c}-0.78883 \\
0.53550 \\
-0.16843 \\
-0.00848 \\
1.33462\end{array}$ & $\begin{array}{cc}3 & -0.58004 \\
& 0.79595 \\
3 & -0.77458 \\
8 & -1.02091 \\
0 & 0.36518\end{array}$ & $\left.\begin{array}{cc}4 & 0.38422 \\
& 1.54875 \\
8 & -1.16229 \\
1 & 0.86437 \\
& 0.35820\end{array}\right]$ & & \\
\hline$W_{3}=$ & $\begin{array}{c}-0.39408 \\
0.49148 \\
-0.23179 \\
-0.06170 \\
0.12877\end{array}$ & $\begin{array}{c}-1.05253 \\
-1.34799 \\
0.61450 \\
-0.63832 \\
0.96213\end{array}$ & $\begin{array}{l}0.92820 \\
1.32417 \\
0.61442 \\
1.63296 \\
0.17480\end{array}$ & $\begin{array}{c}-0.99225 \\
-2.23282 \\
0.96829 \\
0.79919 \\
-0.91970\end{array}$ & $\left.\begin{array}{c}0.80445 \\
0.50508 \\
-0.11020 \\
0.46574 \\
-1.56047\end{array}\right]$ & & \\
\hline$W_{4}=[$ & $-0.14984-$ & -1.74079 & 1.677721 & 1.288301 .20 & $20115]$ & & \\
\hline
\end{tabular}

\begin{tabular}{|c|c|c|c|c|c|c|c|}
\hline$x_{i, \text { offset }}=$ & $=\left[\begin{array}{r}110.0250 \\
1.62025 \\
1.50925 \\
0.10040\end{array}\right.$ & & $x_{i, \text { gain }}=$ & $=\left[\begin{array}{l}0.04004 \\
0.10887 \\
0.10832 \\
2.50250\end{array}\right.$ & & & \\
\hline \multicolumn{3}{|c|}{$y_{o, \text { offset }}=1.64436$} & \multicolumn{2}{|c|}{$y_{o, \text { gain }}=0.99020$} & & & \\
\hline$b_{1}=$ & $\left.\begin{array}{c}2.13081 \\
-1.25447 \\
0.12572 \\
1.53450 \\
3.03466\end{array}\right]$ & & $b_{2}=$ & $\begin{array}{c}-2.03300 \\
1.44868 \\
-0.29829 \\
1.07395 \\
1.23545\end{array}$ & $b_{3}=$ & $\begin{array}{c}1.88959 \\
0.58858 \\
-0.05838 \\
-1.57365 \\
2.03012\end{array}$ & $b_{4}=0.65926$ \\
\hline$W_{1}=$ & $\begin{array}{c}-1.71847 \\
0.14315 \\
0.43550 \\
0.19476 \\
-0.09295\end{array}$ & $\begin{array}{c}0.30526 \\
-0.99297 \\
0.08128 \\
-1.16424 \\
-0.87810\end{array}$ & $\begin{array}{c}-0.01004 \\
-0.00813 \\
-0.01607 \\
0.10822 \\
0.98216\end{array}$ & $\begin{array}{c}-0.03836 \\
-0.00986 \\
-0.02622 \\
0.07762 \\
1.60080\end{array}$ & & & \\
\hline$W_{2}=$ & $\begin{array}{c}0.83447 \\
-0.87178 \\
-0.41707 \\
0.88588 \\
0.80325\end{array}$ & $\begin{array}{c}-1.31102 \\
0.53373 \\
-1.03699 \\
-0.75765 \\
0.09380\end{array}$ & $\begin{array}{c}-0.53128 \\
-0.40729 \\
0.50613 \\
-0.39753 \\
-1.66384\end{array}$ & $\begin{array}{c}0.58080 \\
-1.09208 \\
-0.36636 \\
-1.88193 \\
-0.21748\end{array}$ & $\left.\begin{array}{c}-1.43636 \\
-0.10281 \\
0.71042 \\
-1.02915 \\
-0.53330\end{array}\right]$ & & \\
\hline$W_{3}=$ & $\begin{array}{c}-1.06123 \\
-1.30634 \\
0.29427 \\
-0.66960 \\
0.51903\end{array}$ & $\begin{array}{c}-0.18605 \\
0.96202 \\
-1.66571 \\
0.29632 \\
0.92214\end{array}$ & $\begin{array}{c}-2.00030 \\
-1.92346 \\
0.20669 \\
-0.31867 \\
-1.04580\end{array}$ & $\begin{array}{c}-0.07764 \\
0.20636 \\
0.95220 \\
-0.94652 \\
0.33136\end{array}$ & $\left.\begin{array}{c}-1.29315 \\
-0.09881 \\
0.92256 \\
0.65731 \\
-0.63867\end{array}\right]$ & & \\
\hline$W_{4}=[$ & -1.707590 & $0.62563-c$ & $0.09762-1$ & $1.10884-1$ & $1.18112]$ & & \\
\hline
\end{tabular}


Table 15 Neural network data for full penetration joints, tension loading, $\rho=0.05 \mathrm{~mm}$
Table 16 Neural network data for full penetration joints, bending loading, $\rho=1.00 \mathrm{~mm}$

\begin{tabular}{|c|c|c|c|c|c|c|c|}
\hline$x_{i, \text { offset }}=$ & $=\left[\begin{array}{r}110.0250 \\
0.25238 \\
0.25238 \\
0.10040\end{array}\right.$ & & $x_{i, g \text { ain }}=$ & $=\left[\begin{array}{l}0.04004 \\
0.42147 \\
0.42232 \\
2.50250\end{array}\right.$ & & & \\
\hline \multicolumn{3}{|c|}{$y_{o, \text { offset }}=7.88860 E-13$} & \multicolumn{2}{|c|}{$y_{o, \text { gain }}=0.47092$} & & & \\
\hline$b_{1}=[$ & $\left.\begin{array}{c}1.38074 \\
1.14626 \\
0.25851 \\
-2.07276 \\
-1.35626\end{array}\right]$ & & $b_{2}=$ & $\begin{array}{c}-1.91789 \\
-0.80858 \\
0.19543 \\
-0.96326 \\
-2.12979\end{array}$ & $b_{3}=$ & $\left.\begin{array}{c}-1.96108 \\
-1.07827 \\
0.18003 \\
0.85566 \\
2.04152\end{array}\right]$ & $b_{4}=0.69596$ \\
\hline$W_{1}=$ & $\begin{array}{c}-1.08722 \\
-1.13488 \\
1.22694 \\
-0.01705 \\
-0.68938\end{array}$ & $\begin{array}{c}0.13071 \\
-1.36691 \\
0.37828 \\
-1.16648 \\
1.29152\end{array}$ & $\begin{array}{l}-0.02262 \\
-0.95868 \\
-0.62815 \\
-0.03054 \\
-0.03971\end{array}$ & $\left.\begin{array}{c}0.00943 \\
0.51905 \\
1.34176 \\
0.07017 \\
-0.00535\end{array}\right]$ & & & \\
\hline$W_{2}=$ & $\begin{array}{c}0.38829 \\
1.61804 \\
0.80894 \\
-0.52256 \\
-1.07802\end{array}$ & $\begin{array}{c}-0.05238 \\
0.10663 \\
0.36790 \\
0.98236 \\
0.07905\end{array}$ & $\begin{array}{c}0.03802 \\
-0.14782 \\
-0.19685 \\
0.44280 \\
-0.47301\end{array}$ & $\begin{array}{c}-1.31242 \\
0.42953 \\
1.00284 \\
0.30795 \\
-0.69965\end{array}$ & $\left.\begin{array}{c}0.19868 \\
0.74931 \\
-1.35807 \\
-1.08856 \\
1.19837\end{array}\right]$ & & \\
\hline$W_{3}=$ & $\begin{array}{c}1.30471 \\
1.65298 \\
-1.31203 \\
0.95156 \\
1.02783\end{array}$ & $\begin{array}{c}-0.25925 \\
0.00269 \\
-0.29506 \\
-1.12236 \\
0.54741\end{array}$ & $\begin{array}{c}0.65447 \\
0.37120 \\
0.03984 \\
-0.74351 \\
-0.52435\end{array}$ & $\begin{array}{c}-0.24550 \\
0.36215 \\
0.16727 \\
-0.54731 \\
-0.25411\end{array}$ & $\left.\begin{array}{c}-1.20760 \\
-0.98153 \\
0.81617 \\
-0.98864 \\
0.80275\end{array}\right]$ & & \\
\hline
\end{tabular}


Table 17 Neural network data for full penetration joints, bending loading, $\rho=0.30 \mathrm{~mm}$

\begin{tabular}{|c|c|c|c|c|c|c|c|}
\hline$x_{i, \text { offset }}=$ & $=\left[\begin{array}{r}110.075 \\
1.6942 \\
1.6572 \\
0.1012\end{array}\right.$ & & $x_{i, \text { gain }}=$ & $=\left[\begin{array}{l}0.04008 \\
0.10964 \\
0.10909 \\
2.50501\end{array}\right]$ & & & \\
\hline \multicolumn{3}{|c|}{$y_{o, \text { offset }}=1.70059$} & \multicolumn{2}{|c|}{$y_{o, \text { gain }}=0.67532$} & & & \\
\hline$b_{1}=$ & $\begin{array}{c}2.07202 \\
-0.71703 \\
0.86586 \\
1.47502 \\
1.74898\end{array}$ & & $b_{2}=$ & $\left.\begin{array}{c}1.70881 \\
-0.75112 \\
0.32752 \\
-0.49243 \\
-1.89602\end{array}\right]$ & $b_{3}=$ & {$\left[\begin{array}{c}1.77048 \\
-1.32134 \\
0.24061 \\
-2.11095 \\
-1.58520\end{array}\right]$} & $b_{4}=-0.91851$ \\
\hline$W_{1}=$ & $\begin{array}{c}-0.65933 \\
0.35745 \\
0.02481 \\
0.18557 \\
0.31851\end{array}$ & $\begin{array}{c}-0.28209 \\
0.03914 \\
0.31598 \\
-0.33631 \\
-0.68371\end{array}$ & $\begin{array}{c}-0.01241 \\
0.00299 \\
0.00294 \\
0.64000 \\
0.96568\end{array}$ & $\left.\begin{array}{c}-0.14996 \\
0.01215 \\
-0.00191 \\
0.64233 \\
0.35313\end{array}\right]$ & & & \\
\hline$W_{2}=$ & $\begin{array}{c}-0.10760 \\
1.21814 \\
-0.06392 \\
-0.43356 \\
-0.26405\end{array}$ & $\begin{array}{c}0.56584 \\
-1.08944 \\
-0.80629 \\
-2.06808 \\
50.42376\end{array}$ & $\begin{array}{c}-1.98384 \\
-1.24771 \\
-0.84312 \\
0.33505 \\
-0.95184\end{array}$ & $\begin{array}{cc}4 & 2.23201 \\
1 & -1.67719 \\
2 & 1.21709 \\
& -0.66776 \\
4 & -1.07987\end{array}$ & $\left.\begin{array}{c}-1.79552 \\
0.97521 \\
-0.78558 \\
-0.30975 \\
-1.08719\end{array}\right]$ & & \\
\hline$W_{3}=$ & $\begin{array}{c}0.52111 \\
0.25004 \\
-1.49478 \\
0.88150 \\
-1.66846\end{array}$ & $\begin{array}{c}1.37444 \\
-0.74428 \\
-1.58103 \\
2.14731 \\
-0.93697\end{array}$ & $\begin{array}{c}-0.93052 \\
-0.56135 \\
2.08998 \\
2.21917 \\
1.89496\end{array}$ & 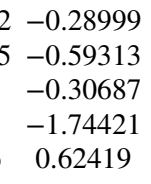 & $\left.\begin{array}{c}-0.10442 \\
-0.24936 \\
-0.19045 \\
0.84367 \\
-0.27932\end{array}\right]$ & & \\
\hline
\end{tabular}

Table 18 Neural network data for full penetration joints, bending loading, $\rho=0.05 \mathrm{~mm}$

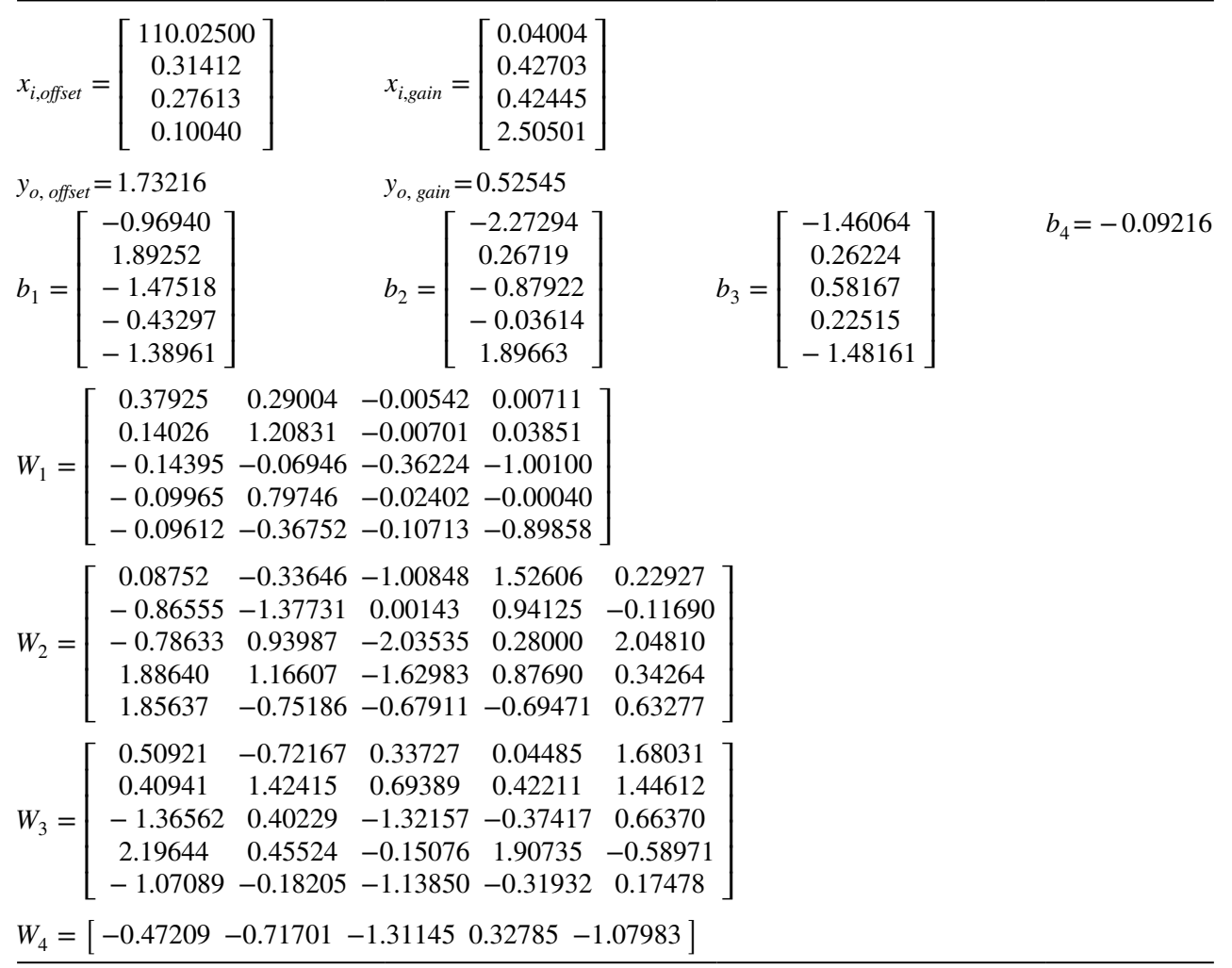


Acknowledgements The IGF project $19450 \mathrm{~N}$ of FOSTA - Forschungsvereinigung Stahlanwendung e. V., Düsseldorf, is funded by the Federal Ministry of Economic Affairs and Energy via the AiF within the framework of the program for the promotion of the Industrielle Gemeinschaftsforschung (IGF) based on a resolution of the German Bundestag. The financial support is greatly acknowledged.

Funding Open Access funding enabled and organized by Projekt DEAL

\section{Declarations}

Conflict of interest The authors declare no competing interests.

Open Access This article is licensed under a Creative Commons Attribution 4.0 International License, which permits use, sharing, adaptation, distribution and reproduction in any medium or format, as long as you give appropriate credit to the original author(s) and the source, provide a link to the Creative Commons licence, and indicate if changes were made. The images or other third party material in this article are included in the article's Creative Commons licence, unless indicated otherwise in a credit line to the material. If material is not included in the article's Creative Commons licence and your intended use is not permitted by statutory regulation or exceeds the permitted use, you will need to obtain permission directly from the copyright holder. To view a copy of this licence, visit http://creativecommons.org/licenses/by/4.0/.

\section{Refernces}

1. Hobbacher A, (2016) Recommendations for fatigue design of welded joints and components - IIW document IIW-2259-15 ex XIII-2460-13/XV-1440-13, Springer Verlag.

2. DVS - Deutscher Verband für Schweißen und verwandte Verfahren e. V (2017) Merkblatt DVS 0905 - Industrielle Anwendung des Kerbspannungskonzeptes für den Ermüdungsfestigkeitsnachweis von Schweißverbindungen. DVS Media GmbH, Düsseldorf

3. Baumgartner J, Hobbacher AF, Rennert R (2020) Fatigue assessment of welded thin sheets with the notch stress approach - Proposal for recommendations. Int J Fatigue 140:105844

4. Karakas Ö, Morgenstern C, Sonsino CM (2008) Fatigue design of welded joints from the wrought magnesium alloy AZ31 by the local stress concept with the fictitious notch radii of $\mathrm{rf}=1.0$ and $0.05 \mathrm{~mm}$. Int J Fatigue 30:2210-2219

5. Karakas Ö, Baumgartner J, Susmel L (2020) On the use of a fictitious notch radius equal to $0.3 \mathrm{~mm}$ to design against fatigue welded joints made of wrought magnesium alloy AZ31. Int J Fatigue 139:105747

6. Bruder T, Störzel K, Baumgartner J, Hanselka H (2012) Evaluation of nominal and local stress based approaches for the fatigue assessment of seam welds. Int J Fatigue 34:86-102

7. Köttgen VB, Olivier R and Seeger T, (1991) "Fatigue analysis of welded connections based on local stresses," in IIW XIII-1408-91.

8. Radaj D (1990) Design and analysis of fatigue resistant welded structures. Abington, Cambridge

9. Neuber H (1968) Über die Berücksichtigung der Spannungskonzentration bei Festigkeitsberechnungen. Konstruktion 20(7):245-251
10. Renken F, von Bock und Polach RUF, Schubnell J, Jung M, Oswald M, Rother K, Braun M (2021) An algorithm for statistical evaluation of weld toe geometries using laser triangulation. Int J Fatigue 149:106293

11. Alam MM, Barsoum Z, Jonsen P, Kaplan AFH, Häggblad HA (2010) The influence of surface geometry and topography on the fatigue cracking behaviour of laser hybrid welded eccentric fillet joints. Appl Surf Sci 256:1936-1945

12. Liinalampi S, Remes H, Lehto P, Lillemäe I, Romanoff J, Porter D (2016) Fatigue strength analysis of laser-hybrid welds in thin plate considering weld geometry in microscale. Int J Fatigue 87:143-152

13. Ottersböck MJ, Leitner M, Stoschka M (2021) Characterisation of actual weld geometry and stress concentration of butt welds exhibiting local undercuts. Eng Struct 240:112266

14. Oswald M, Rother K, Mayr C (2019) Determination of notch factors for welded cruciform joints based on numerical analysis and metamodeling. Weld World 63(5):1339-1354

15. Oswald M, Rother K, Neuhäusler J (2020) Determination of notch factors for welded butt joints based on numerical analysis and metamodeling. Weld World 64(3):2053-2074

16. Oswald M, Springl S and Rother K, (2020) "Determination of notch factors for welded T-joints based on numerical analysis and metamodeling," Int Inst Weld IIW-Doc-XIII-2853-2020.

17. Tsuji I (1990) Estimation of stress concentration factor at weld toe of non-load carrying fillet welded joints. West Jpn SocNaval Arch 80:241-251

18. Monahan CC, (1995) "Early fatigue crack growth at welds," Topics in Engineering. Comp Mech Publ 26.

19. Brennan FP, Peleties P, Hellier AK (2000) Predicting weld toe stress concentration factors for $\mathrm{T}$ and skewed $\mathrm{T}$-joint plate connections. Int J Fatigue 22:573-584

20. Hellier AK, Brennan FP, Carr DG (2014) Weld Toe SCF and Stress Distribution Parametric Equations for Tension (Membrane) Loading. Adv Mater Res 891-892:1525-1153

21. Dabiri M, Ghafouri M, Rohani Raftar HR, Björk T (2017) Neural network-based assessment of the stress concentration factor in a T-welded joint. J Constr Steel Res 128:567-578

22. Sonsino CM (2009) Principles of local stress concepts for the assessment of welded joints. ESIS Newslett 45:30-34

23. Hagan MT, Demuth HB, M. Beale and O. De Jesus, Neural network design.

24. Rother K, Fricke W (2016) Effecitve notch stress approach for welds having low stress concentration. Int J Press Vessel Pip 147:12-20

25. Rother K, "SCF-Predictor," [Online]. Available: http://rother. userweb.mwn.de/scf-predictor.html. [Accessed 23 June 2021].

26. Leitner M, Stoschka M, Ottersböck M (2017) Fatigue assessment of welded and high frequency mechanical impact (HFMI) treated joints by master notch stress approach. Int J Fatigue 101:232-243

27. Schnabel K, Baumgartner J, Möller B (2019) Fatigue Assessment of Additively Manufactured Metallic Structures Using Local Approaches Based on Finite-Element Simulations. Proc Struct Integr 19:442-451

28. Hesseler J, Baumgartner J, Bleicher C (2021) Consideration of the transient material behavior under variable amplitude loading in the fatigue assessment of nodular cast iron using the strain-life approach. Fatigue Fract Eng Mater Struct 44:2845-2857. 1-13

Publisher's note Springer Nature remains neutral with regard to jurisdictional claims in published maps and institutional affiliations. 